\title{
Cigarette tar content and symptoms of chronic bronchitis: results of the Scottish Heart Health Study
}

\author{
C A Brown, I K Crombie, W C S Smith, Hugh Tunstall-Pedoe
}

\begin{abstract}
Study objective-The aim was to determine if there was a relationship between cigarette tar yield and rates of chronic cough and chronic phlegm.

Setting-22 districts across Scotland were used for the Scottish Heart Health Study (SHHS) which was conducted between 1984 and 1986 and from which the data for this analysis were obtained.
\end{abstract}

Subjects-10 359 men and women aged 40-59 years were studied. Of these, 2801 current cigarette smokers whose brand of cigarette smoked was known were selected.

Measurements and main results-Data on self reported smoking habits and prevalence of chronic cough and chronic phlegm were obtained from the SHHS. Tar yield was divided into three groups: low $(\leqslant 12 \mathrm{mg}$ / cigarette); middle (13-14 mg/cigarette); high ( $\geqslant 15 \mathrm{mg} /$ cigarette). The average tar yield consumed per person was $13.2 \mathrm{mg} /$ cigarette. Women in the middle and high tar groups had smoked for longer and had significantly higher breath carbon monoxide levels, serum thiocyanate levels, serum cotinine levels, and daily cigarette consumption than the women in the low tar group. This pattern was not seen in men for any of these five smoking variables. Rates of chronic cough and chronic phlegm were higher with higher tar yield of cigarettes smoked for women (low tar $v$ high tar: $p<0.001$ ) but not for men. Daily cigarette consumption and the number of years of smoking were the most significant risk factors for chronic cough and chronic phlegm for both men and women. Tar was still a significant risk factor $(p<0.05)$ for women after controlling for these two risk factors and social class.

Conclusions-Both sexes show strong effects of daily cigarette consumption and years of smoking on respiratory symptoms; women show an additional effect of cigarette tar content while men do not. The spread of tar yield in both sexes was small but there were more women on low tar cigarettes and this may have enabled a weak effect of tar to be seen better in them. On the other hand, tar level in women was confounded with other factors. Statistical methods of controlling for this may not have removed this confounding completely.

Committed cigarette smokers unwilling to give up smoking have been advised to change to cigarettes with a lower tar yield. ${ }^{1-3}$ In the UK, mortality from chronic bronchitis has been falling ${ }^{4}$ as have smoking rates, ${ }^{5}$ and the average tar yield $(\mathrm{mg})$ has more than halved from $30.4 \mathrm{mg} /$ cigarette in 1955 to $14.4 \mathrm{mg} /$ cigarette in $1985^{6}$ in the past 30 years. Scotland has one of the highest rates of death from diseases of the respiratory system in the developed world. ${ }^{7}$ Cigarette smoking is accepted as the main cause of chronic bronchitis in the $\mathrm{UK}^{8}$ with an increase in symptoms corresponding to an increase in cigarette consumption. ${ }^{910}$ Given this strong dose-response relationship, this paper addresses the question of whether there are benefits associated with smoking cigarette brands with a lower tar yield.

This paper uses data from a large cross sectional survey, the Scottish Heart Health Study (SHHS), ${ }^{11}$ and looks at cigarette tar group and the prevalence of chronic cough and chronic phlegm, which are two major symptoms of chronic bronchitis. No study of a comparable size has looked at the link between tar yield of cigarettes and the frequency of these symptoms in the two sexes.

\section{Methods}

Data were taken from the SHHS, ${ }^{12}{ }^{13}$ a study set up to investigate the high levels of coronary heart disease mortality in Scotland. Twenty two districts of mainland Scotland were chosen, at least one and usually two from each of the Health Board areas. Glasgow City was split into two. Glasgow north of the Clyde and also the City of Edinburgh were chosen for an overlapping longitudinal study (the WHO MONICA study). ${ }^{14}$ The subjects were 2801 men and women in the $40-59$ years age group who were current cigarette smokers (395 cigar and/or pipe smokers and 775 for whom tar content of the cigarettes smoked was unknown were removed from the analysis). A self completed questionnaire was sent to each subject together with an appointment to attend a survey clinic for examination. The data presented in this paper come from three sections of the questionnaire: the personal history section; the British Medical Research Council respiratory questionnaire ${ }^{15}$; and the World Health Organization standard smoking questions $^{16}$ with some additional questions on smoking. Expired air carbon monoxide was measured using a Model 2000 portable carbon monoxide Ecolyser (Analyses Automation) or a EC50 carbon monoxide monitor (Bedfont Technical Instruments) during the examination. A comparison between the two machines showed that they gave very similar results. ${ }^{17} \mathrm{~A}$ blood sample was taken during the examination by a trained nurse for biochemical analysis. This was subsequently analysed for thiocyanate using a COBAS Bio analyser and for cotinine by gas-liquid chromatography. ${ }^{18}$ 
DEFINITION OF TERMS USED

Chronic cough was defined as cough first thing in the morning and/or at any time during the day or night for as much as three months each year. Chronic phlegm was the bringing up of phlegm from the chest first thing in the morning and/or at any time during the day or night for as much as three months each year. A cigarette smoker is one who describes himself currently as a regular or occasional cigarette smoker. The tar yields of the cigarettes smoked in this study were obtained from a computer file supplied by the Government Chemist covering the period of the survey (as published periodically in tables by the Department of Health). Three categories of tar level were devised to divide the study sample into approximately equal groups: $\leqslant 12 \mathrm{mg} /$ cigarette, $13-14 \mathrm{mg} /$ cigarette, and $\geqslant 15 \mathrm{mg} /$ cigarette. These categories are referred to as low, middle, and high tar respectively in the text. The Government definitions of tar groups were, up to 1984: low ( $\leqslant 10 \mathrm{mg} /$ cigarette), low to middle $(11-16 \mathrm{mg} /$ cigarette), middle (17-22 mg/cigarette), middle to high (23-28 mg/cigarette), and high ( $\geqslant 29 \mathrm{mg}$ cigarette). ${ }^{1}$ These were redefined from 1 st January 1985 as follows: low ( $\leqslant 9 \mathrm{mg} /$ cigarette), low to middle (10-14 mg/cigarette), middle (15-17 mg/ cigarette), and high ( $\geqslant 18 \mathrm{mg} /{\text { cigarette) } .^{2}}^{2}$

Social class was defined using the OPCS 1980 Classification of Occupations, ${ }^{18}$ with the social class for married women based on their husband's occupation.

\section{STATISTICAL METHODS}

Variables describing potential risk factors were fitted into multiple logistic regression models separately to predict the presence of chronic cough or chronic phlegm. For daily cigarette consumption, the values were divided into three standard groups: < 15 cigarettes/day, 15-24 cigarettes/day, and $\geqslant 25$ cigarettes/day. ${ }^{9}$ For number of years smoked, the values were divided into three approximately equal groups. This was done separately for men and women. A $t$ test was used to test the significance of the differences between group means. A test for differences in proportions examined differences between rates of chronic cough and chronic phlegm in the three tar groups for both men and women.

\section{Results}

The distribution of tar yields for the 2801 current cigarette smokers (1154 men and 1647 women) investigated in this study is shown in table $I$. Despite using arbitrary cut off points in an attempt to equalise the three tar groups, the large clustering of subjects at the $13 \mathrm{mg} /$ cigarette and the 14 $\mathrm{mg} /$ cigarette means that there is a large number of subjects in the middle tar group and a smaller number in the low tar group. Of the men, $11.4 \%$ (131) were in the low tar group, $47.7 \%$ (550) in the middle group, and $41.0 \%$ (473) were in the high group; $25.0 \%(411)$ of the women were in the low tar group, $41.5 \%(684)$ in the middle group, and $33.5 \%(532)$ in the high group. The distribution of smokers by past and present Government tar groups is also shown in table I. Approximately $72 \%$ of the men in the low tar group, $27 \%$ in the middle tar group, and $20 \%$ in the high tar group
Table I Distribution of the tar yields of cigarettes smoked by men and women

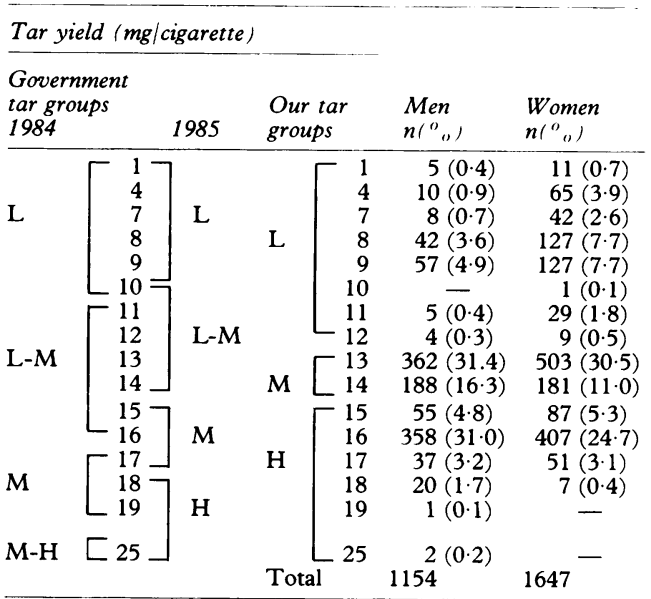

$\mathrm{L}=$ low; $\mathrm{L}-\mathrm{M}=$ low to middle; $\mathrm{M}=$ middle; $\mathrm{M}-\mathrm{H}=$ middle to high; $\mathrm{H}=$ high

reported that they had changed to smoking a cigarette with a lower tar yield in the last 10 years. The corresponding percentages for women are $73^{\circ}, 35^{\circ}$, and $24^{\circ}{ }_{0}$.

In each of the tar groups, men have a higher mean tar value than women $(8.04 v 7.69,13.34 v$ 13.26 , and $16.09 v 15.96$ for low, middle, and high tar groups respectively) although these differences are small. Analyses comparing tar means in each of the four age groups $(40-44,45-49,50-54$, and 55-59 years) and the proportion of subjects in each of three tar groups by age group showed little difference for both men and women. None of the rates and means presented have been age standardised because of the lack of an age effect. Table II shows that among women, the three biochemical measurements (carbon monoxide, thiocyanate, and cotinine), the daily cigarette consumption, and the number of years of smoking were all significantly higher for subjects in the middle and high tar groups than in the low tar group. However, the biochemical measurements show no difference between the middle and high tar groups for the women. Among men, the only significant differences are between the low and middle groups for carbon monoxide, and between the low and high groups for thiocyanate.

Table III shows the biochemical measurements expressed as levels per cigarette in the three tar groups, and a similar pattern to that shown in table II emerged. Among men no difference was significant. Among women, the same trend for carbon monoxide and cotinine was shown, but the trend for thiocyanate was in the opposite direction with higher mean values in the low and middle tar groups compared with the high tar group.

The rates of chronic cough and chronic phlegm show a strong relationship with tar group among women, with higher rates in the middle and high tar groups. Among men, there was a similar though less marked pattern for rates of chronic cough, but not for chronic phlegm (table IV). A similar pattern was observed with winter cough and phlegm which did not persist for as long as three months each year.

Table $\mathrm{V}$ shows the results of fitting a multiple logistic model which is used to predict the presence of the chronic bronchitis symptoms among men and women using a number of risk factors. Daily 
cigarette consumption and the number of years of smoking were the strongest risk factors in predicting chronic cough for men. Social class was also significant. For chronic phlegm among men, the same significant risk factors emerged. Tar was not a significant factor for either symptom in men. Among women, daily cigarette consumption and the number of years of smoking were significant for chronic cough, as were tar content and social class. For chronic phlegm among women, social class was not a significant factor. The analysis was redone for men and women with tar, daily cigarette consumption, and number of years of smoking as continuous variables and the results were essentially the same.

\section{Discussion}

This study shows that women who smoke cigarettes in a low tar group have lower rates of chronic bronchitis symptoms than women who smoke cigarettes in a high tar group. The same is not true for men. The results also confirm that daily cigarette consumption and the number of years of smoking are far stronger risk factors for chronic bronchitis symptoms than the tar yield of the cigarette smoked.

The accuracy of self reporting of respiratory symptoms may be of concern although the MRC respiratory questionnaire is a widely used and reliable method for ascertaining the actual respiratory symptoms. ${ }^{20}$ Information on changing cigarette brand over the past 10 years revealed that almost three quarters of the subjects in the low tar group and one third of those in the middle tar group reported that they had previously smoked a cigarette with a higher tar
Table II Mean levels of three biochemical measures of smoking, daily cigarette consumption, and the number of years smoked by tar group for men and women. Values are means $195 \%$ confidence intervals)

\begin{tabular}{llll}
\hline & $\begin{array}{l}\text { Tar group } \\
\text { (mg/cigarette) }\end{array}$ & Men & Women \\
\hline Carbon & $\leqslant 12$ & $22(19,24)$ & $18(17,19)$ \\
monoxide & $13-14$ & $26(25,27) \dagger$ & $23(22,24) \ddagger$ \\
(ppm) & $\geqslant 15$ & $24(23,25)$ & $23(22,24) \ddagger$ \\
Thiocyanate & $\leqslant 12$ & $114(106,121)$ & $120(115,124)$ \\
( $\mu$ mol/litre) $)$ & $13-14$ & $117(114,121)$ & $136(132,139) \ddagger$ \\
& $\geqslant 15$ & $122(118,125)^{\star}$ & $138(134,142) \ddagger$ \\
Cotinine & $\leqslant 12$ & $275(246,304)$ & $199(185,213)$ \\
(nmol/litre) & $13-14$ & $293(279,306)$ & $271(259,283) \ddagger$ \\
& $\geqslant 15$ & $278(265,292)$ & $269(256,283) \ddagger$ \\
Daily & $\leqslant 12$ & $20(18,22)$ & $15(15,16)$ \\
cigarette & $13-14$ & $22(21,22)$ & $17(17,18) \ddagger$ \\
consumption & $\geqslant 15$ & $21(20,22)$ & $18(17,19) \ddagger$ \\
& & $34(32,35)$ & $30(29,31)$ \\
Number of & $\leqslant 12$ & $34(33,34)$ & $31(31,32) \star$ \\
years & $13-14$ & $34(34)$ \\
smoked & $\geqslant 15$ & $34(33,35)$ & $32(31,32) \ddagger$ \\
\hline
\end{tabular}

The $t$ test comparison is made between low tar $v$ middle groups and low $\operatorname{tar} v$ high tar groups $\neq \mathrm{p}<0.001,+\mathrm{p}<0.01, \star_{\mathrm{p}}<0.05$

Table III Mean levels of three biochemical measures of smoking, corrected for daily cigarette consumption. Values are means $\left(95^{\circ}\right.$ 。 confidence intervals) yield. There were more women than men in the middle and high tar groups who had switched to a cigarette with a lower tar yield. Previous tar group however is not known and this study is purely based on the tar yield of cigarettes currently smoked. One limitation in comparing the effects between tar groups in this report and those of other studies is that different studies use different tar group definitions. Older surveys extended to much higher tar yields than those of today and the spread of tar yields was greater, but in all cases higher tar levels are being compared with lower tar levels. Some studies compare plain cigarettes with filter cigarettes with the assumption that the former deliver more tar than the latter.

In this study, as in that by Paoletti et al, ${ }^{21}$ there is no age trend associated with tar group. Russell et $a l^{22}$ found that both men and women in older age groups were more likely to smoke low tar cigarettes than those in younger age groups, whereas Schenker et $a l^{9}{ }^{9}$ who looked at women, found the opposite. However these studies had a wider age range than our study.

Our results show little difference for men in measurements of carbon monoxide, thiocyanate, and cotinine between the three tar groups, a finding previously reported for both men and women by Jaffe et al. ${ }^{23}$ Some surveys have suggested that those who switch to cigarettes in a lower tar group may inhale more from a cigarette to compensate for the lower tar yield. Two studies showed that those in the lower tar groups had higher carboxyhaemoglobin levels (carbon monoxide in the blood) than those in the higher tar groups. ${ }^{24} 25$ Other studies show higher biochemical measurements in the higher tar groups than the low tar groups ${ }^{26}$ although there is evidence of greater inhalation in the lower groups. ${ }^{22} 27$ Among women in the present study, there are significantly higher biochemical measurements, with greater amounts of carbon monoxide and cotinine per cigarette in the higher tar groups. This study suggests that women have not increased their smoking inhalation enough to compensate for smoking cigarettes with a lower tar yield and this could in part explain the greater chronic bronchitis rates in the higher tar groups. It is worth reiterating that the pattern of change of switching to cigarettes with a lower tar yield is the same in both sexes. Lynch and Benowitz ${ }^{28}$ showed higher levels of carbon monoxide and nicotine in the higher tar group due to greater intake per cigarette.

Another method of "compensation" is for those in a lower tar group to smoke more cigarettes. ${ }^{26} 27$ The majority of studies show no relationship between tar content and daily cigarette consumptions, ${ }^{21-2325} 29$ and this was true for the men in our study. Among women, however, there was a significantly higher daily consumption of cigarettes in the higher tar groups, as was found by Lynch and Benowitz. ${ }^{28}$

Our results confirm the findings of two other studies ${ }^{920}$ that women who smoke cigarettes with a high tar yield have higher chronic bronchitis rates than those who smoke cigarettes with a low tar yield. Among men, there is no apparent difference in chronic bronchitis rates between tar groups. This finding contrasts with the results of both Higenbottam et al, ${ }^{10}$ who found high tar 
Table IV Prevalence of chronic bronchitis symptoms by tar group among men and women. Values in brackets are numbers of cases

Table $V$ The relative odds from a multiple logistic model predicting the incidence of chronic cough and chronic phlegm among men and women.

\begin{tabular}{|c|c|c|}
\hline $\begin{array}{l}\text { Tar group } \\
\text { (mg/cigarette) }\end{array}$ & Male & Female \\
\hline $\begin{array}{l}\leqslant 12 \\
13-14 \\
\geqslant 15\end{array}$ & $\begin{array}{l}\text { Chronic cough } \\
26 \cdot 8^{\circ}{ }_{0}(34) \\
33 \cdot 0^{\circ}(176) \\
31 \cdot 2^{\circ}{ }_{0}(139)\end{array}$ & $\begin{array}{l}18 \cdot 4^{\circ} \circ(72) \\
23 \cdot 6^{\circ}(153)^{\star} \\
30 \cdot 0^{\circ} \circ(158) \neq\end{array}$ \\
\hline $\begin{array}{l}\leqslant 12 \\
13-14 \\
\geqslant 15\end{array}$ & $\begin{array}{l}\text { Chronic phlegm } \\
29 \cdot 4^{\circ} \circ(37) \\
30.9^{\circ} \circ(165) \\
29 \cdot 8^{\circ} \circ(137)\end{array}$ & $\begin{array}{l}17 \cdot 2^{\circ} \circ(68) \\
18 \cdot 8^{\circ} \circ(123) \\
28.5^{\circ} \circ(152) \ddagger\end{array}$ \\
\hline
\end{tabular}

The test for differences in proportions is between the low tar $v$ middle tar groups and the low tar $v$ high tar groups $\neq \mathrm{p}<0.001,{ }_{\mathrm{p}}<0.05$

\begin{tabular}{|c|c|c|c|c|}
\hline & \multicolumn{2}{|c|}{ Chronic cough } & \multicolumn{2}{|c|}{ Chronic phlegm } \\
\hline & Men & Women & Men & Women \\
\hline \multicolumn{5}{|l|}{ Tar content } \\
\hline Low & 1.00 & 1.00 & 1.00 & 1.00 \\
\hline Middle & 1.04 & 1.00 & 0.94 & 0.93 \\
\hline \multirow{2}{*}{\multicolumn{5}{|c|}{ Daily consumption }} \\
\hline & & & & \\
\hline Low & $1 \cdot 00$ & 1.00 & 1.00 & 1.00 \\
\hline Middle & $1.56 \pm$ & $1.54 \ddagger$ & $1 \cdot 23^{\star}$ & $1.43 t$ \\
\hline \multirow{2}{*}{\multicolumn{5}{|c|}{ No of years smoking }} \\
\hline & & & & \\
\hline Low & 1.00 & 1.00 & 1.00 & 1.00 \\
\hline Middle & $1.27 \dagger$ & 1.08 & $1 \cdot 16$ & $1 \cdot 21^{\star}$ \\
\hline High & $1.68 \ddagger$ & $1 \cdot 28 t$ & $1.55 \ddagger$ & $1.42 \pm$ \\
\hline \multicolumn{5}{|l|}{ Social class } \\
\hline Non-manual & 1.00 & 1.00 & 1.00 & 1.00 \\
\hline Manual & $1 \cdot 41 \neq$ & $1 \cdot 26 t$ & $1 \cdot 34 t$ & $1 \cdot 14$ \\
\hline
\end{tabular}

The groupings for each variable are as follows: tar (mgcigarette): low $=\leqslant 12$, middle $=13-14$, high $=\geqslant 15$; daily cigarette consumption: low $=<15, \quad$ middle $=15-24$, high $=\geqslant 25$; number of years of smoking (men): low $=\leqslant 30$, middle $=31-37, \quad$ high $=\geqslant 38 ; \quad$ (women): low $=\leqslant 27$, middle $=28-34$, high $=\geqslant 35$

The $t$ test comparison is made between the low $v$ middle groups and the low $v$ high groups. For social class, the $t$ test comparison is made between non-manual and manual

$\neq \mathrm{p}<0.001, \mathrm{tp}<0.01,{ }^{\star} \mathrm{p}<0.05$

cigarette smokers had a higher prevalence of phlegm production, and Paoletti et al. ${ }^{21}$ Hawthorne and Fry, ${ }^{30}$ who looked at persistent phlegm in both men and women, found little difference in rates between tar groups, and Petitti and Friedman, ${ }^{31}$ who studied several respiratory diseases, found little difference in the chronic bronchitis rates between tar groups. Most studies conclude that it is far better to quit smoking ${ }^{91}$ 31-34 $^{\text {to reduce symptoms. }}$

In conclusion, women appear to have higher chronic bronchitis rates in the high tar group compared to the low tar group after controlling for the number of cigarettes smoked per day, the number of years of smoking, and social class, and they consume more carbon monoxide and nicotine in the higher tar groups. Chronic bronchitis rates among men showed no relationship to the tar yield of cigarettes smoked, with daily cigarette consumption and biochemical measurements fairly uniform across tar groups. The reason for the difference between men and women in this respect remain unclear. It may be that the multiple logistic models compensate inadequately for the confounding factors which are present in women but not in men. On the other hand, the larger population of women in the low tar group compared with men enables a true but weak effect to be demonstrated. Daily cigarette consumption and the number of years smoked are much stronger risk factors for chronic bronchitis for both men and women than the tar yield of the cigarette smoked.

The Scottish Heart Health Study was funded by the Scottish Home and Health Department, and the smoking component by the Tobacco Products Research Trust. Opinion expressed are those of the authors and not the funding bodies.
1 Health Departments of the UK. Tar, carbon monoxide and nicotine yields of cigarettes. London: DHSS, 1984.

2 Health Departments of the UK. Tar, carbon monoxide and nicotine yields of cigarettes. London: DHSS, 1986

3 Royal College of Physicians. Health or Smoking? London: Pitman Publishing, 1983.

4 Burney GJ, Holland WW. The epidemiology of respiratory disease in the UK. Int Med 1982; 1: 122-4.

5 General household survey. London: Office of Population Censuses and Surveys, 1985.

6 Wald N, Froggatt P. Nicotine, smoking and the Low Tar Programme. Oxford: Oxford University Press, 1989: 59.

7 World health statistics annual 1987. Geneva: World Health Organization, 1987.

8 Doll R, Peto R. Mortality in relation to smoking: 20 years' observations on male British doctors. BMF 1976; ii: 1515 36.

9 Schenker MB, Samet JM, Speizer FE. Effect of cigarette tar content and smoking habits on respiratory symptoms in women. Am Rev Resp Dis 1982; 125: 684-90.

10 Higenbottam T, Clark TJH, Shipley MJ, Rose G. Lung function and symptoms of cigarette smokers related to tar yield and number of cigarettes smoked. Lancet 1981; i 409-12.

11 Smith WCS, Crombie IK, Tavendale R, Irving JM, Kenice MB, Tunstall-Pedoe H. The Scottish Heart Health Study objectives and development of methods. Health Bull 1987 45: $211-7$.

12 Smith WCS, Tunstall-Pedoe H, Crombie IK, Tavendale R Major risk factor and lifestyle findings from 10,359 men and women in the Scottish Heart Health Study. Scot Med F 1989; 34: 550-5.

13 Tunstall-Pedoe H, Smith WCS, Crombie IK, Tavendale R. Coronary risk factors and lifestyle variation across Scotland: Results from the Scottish Heart Health Study. Scotland: Results from the Sco $\mathcal{F} 1989 ; 34: 556-60$.

14 WHO MONICA Project Principal Investigators (prepared by $\mathrm{H}$ Tunstall-Pedoe). The World Health Organization MONICA Project (monitoring trends and determinants in cardiovascular disease): a major international collaboration f Clin Epidemiol 1988; 41: 105-14.

15 Florey C du V, Leeder SR. Methods of cohort studies of chronic airflow limitation. Copenhagen: World Health Organization, 1982.

16 Rose GA, Blackburn H, Gillum RF, Prineas RJ Cardiovascular survey methods. Geneva: World Health Organization, 1982.

17 Feyerabend C, Russell MAH. Rapid gas-liquid chromatographic determination of cotinine in biological chromatographic determination of
fluids. Analyst 1980; 105: 998-1001.

18 Irving JM, Clark EC, Crombie IK, Smith WCS. Evaluation of a portable measure of expired air carbon monoxide. Prev Med 1987; 17: 109-15.

19 Office of Population Censuses and Surveys. Classification of occupations 1980. London: HMSO, 1980.

20 Withey CH, Price CE, Swan AV, Papacosta AO, Hensley MJ. Repeatability of a questionnaire to assess respiratory symptoms in smokers. $\mathcal{F}$ Epidemiol Community Health 1988 42: 54-9.

21 Paoletti P, Camilli AE, Holberg CJ, Lebowitz MD. Respiratory effects in relation to estimated tar exposure Respiratory effects in relation to estimated tar exposure
from current and cumulative cigarette consumption. Chest from current and cum

22 Russell MAH, Jarvis MJ, Feyerabend C, Saloojee Y Reduction of tar, nicotine and carbon monoxide intake in low tar smokers. F Epidemiol Community Health 1986; 40 $80-5$.

23 Jaffe JH, Kanzler M, Friedman L, Stunkard AJ, Verebey K. Carbon monoxide and thiocyanate levels in low tar/nicotine smokers. Addict Behav 1981; 6: 337-43.

24 Wald NJ, Idle M, Boreham J, Bailey A. Inhaling habits among smokers of different types of cigarette. Thorax 1980; 35: 925-8.

25 Wald NJ, Idle $M$, Boreham J. The importance of tar and nicotine in determining cigarette smoking habits. $f$ Epidemiol Community Health 1981; 35: 23-4.

26 Maron DJ, Fortmann SP. Nicotine yield and measures of cigarette smoke exposure in a large population: are loweryield cigarettes safer? Am $\mathcal{F}$ Public Health 1987; 77: 546-59.

27 Benowitz NL, Jacob P III, Yu L, Talcott R, Hall S, Jones RT. Reduced tar, nicotine, and carbon monoxide exposure while smoking ultralow- but not low-yield cigarettes. fAMA 1986; 256: 241-6.

28 Lynch CJ, Benowitz NL. Spontaneous cigarette brand switching: consequences for nicotine and carbon monoxide exposure. Am $\mathcal{F}$ Public Health; 78: 1191-4.

29 Freedman S, Fletcher CM. Changes of smoking habits and cough in men smoking cigarettes with $30^{\circ}{ }^{\circ}$ NSM tobacco substitute. $B M \mathcal{F} 1976 ; \mathrm{i}: 1427-30$.

30 Hawthorne VM, Fry JS. Smoking and health: the association between smoking behaviour, total mortality, and cardiorespiratory disease in west central Scotland. $\mathscr{f}$ Epidemiol Community Health 1978; 32: 260-6.

31 Petiti DB. Friedman GD. Respiratory morbidity in Petitti DB, Friedman GD. Respiratory morbidity in
smokers of low- and high-yield cigarettes. Prev Med 1985; 14: 217-25.

32 Comstock GW, Brownlow JW, Stone RW, Sartwell PE. Cigarette smoking and changes in respiratory findings. Arch Environ Health 1970; 21 : 50-7.

33 Benowitz NL. Health and public policy implications of the low yield cigarette. $N$ Eng $f$ Med 1989; 320: 1619-21

34 Higenbottam T. The search for the safer cigarettes: stopping smoking is still the answer. $B M \mathcal{F}$ 1989; 299: 994-5. 